\title{
Preliminary Study on the Effect of Halofantrine Hydrochloride on the Testes of Mature Wistar Rats
}

\author{
DIDIA, B.C; GBIGBI, P.S; DAPPER, D.V*. \\ Department of Anatomy and Human Physiology*, College of Health Sciences, University of Port Harcourt, P.M.B. 5323, Port Harcourt \\ Nigeria.
}

\begin{abstract}
Halofantrine hydrochloride is a phenantrine methanol antimalarial which is schizonticidal with a high degree of activity against the asexual erythrocytic stage of malaria parasites. It is indicated for the treatment of acute malaria caused by single or mixed infections of Plasmodium falciparum or Plasmodium vivax. Fifteen male adult rats of Wistar strain (Rattus Norvegicus) weighing between $200-300 \mathrm{~g}$ were divided into three groups of five rats each were used for the study. The first group (Group A) was given $0.05 \mathrm{ml}$ of drug $/ 100 \mathrm{~g}$ of animal body weight; the second group (Group B) was given $0.1 \mathrm{ml}$ of drug/ $100 \mathrm{~g}$ of animal body weight while the third group (Group C; control) was given $0.05 \mathrm{ml}$ of physiological saline/ $100 \mathrm{~g}$ of animal body weight. The drug/physiological saline was given in three doses at six hourly intervals. The rats were all sacrificed on the fifth day following treatment and the testes examined morphologically and histologically after fixing with $10 \%$ formaldehyde. Result obtained showed no statistical gross morphological differences between all the three rat groups with respect to testicular weights and lengths ( $p>0.05$ ). There was however, significant differences between the groups in terms of the testicular width $(p<0.05)$. Histologically, there was increased cellularity with immature spermatocytes in the testes of the experimental rats. These changes apparently were dose dependent.It is therefore concluded that the drug apparently increases spermatogenesis and could cause degenerative changes at higher doses. Whether these changes are reversible is yet to be determined. $O J A S E M$
\end{abstract}

The bid to obtain better treatment for malaria, which is an important tropical disease, has necessitated the production of new anti-malarial drugs. This move became very necessary partly because of the generalized pruritus which follows ingestion of chloroqine in some Negro subjects (Ekpechi and Okoro 1964; Olatunde 1969; Olatunde 1977 and Abila and Ikueze 1989). In Nigeria, generalized pruritus has been reported to occur in about $15 \%$ of acute malaria patients treated with chloroquine (Olatunde 1969; Osifo 1984; Solake 1984). Although chloroquine has been the mainstay of anti-malarial chemotherapy the pruritus it induces is a major problem in Negro patients.

Halofantrine hydrochloride (Halfan) is a new blood schizonticide with a phenanthrene methanol structure. Its use has been on increased in Nigeria, possibly because of the increase incidence of chloroquine resistance noticed in third world countries. (Cook 1988; Sowunmi et al 1989) Although, Halofantrine has also been reported to induce pruritus, reports are conflicting (Hallwood et al 1989; Sowunmi et al 1989). In addition, recent studies in Nigeria has shown that the incidence and intensity of induced prutitus were significantly higher with chloroqine therapy than with Halofantrine therapy (Sowunmi et al 1989). Furthermore, the incidence and intensity of chloriquine induced pruritus were significantly higher in patients with malaria than in healthy subjects (Ezeamuzie et al 1991). By contrast, there was no significant difference between malaria patients and healthy subjects as regards Halofantrine induced pruritus (Ezeamuzie et al 1991)

Recent studies on chloriquine indicate that it could be an approach to the development of a female *Corresponding author contraceptive especially in developing countries (Noronha et al 1991). Chloroquine has also been shown to have teratogenic effects on Leydig cells of mature male wistar rats (Akpa and Singh 1992). Halofantrine exerts its action on the erythrocytic stage of the plasmodium life cycle, i.e on the trophozoite and schizont in red cells. Although, its mechanism of action is still uncertain, it is however believed to be similar to quinine and chloroquine in some respects. If the above is correct, Halofantrine could also have some effect(s) on the testes of experimental animals (Okanlanwo et al 1990).

This study therefore focuses on the effect of Halofantrine on testicular morphology and histology of the mature male wistar rat

\section{MATERIALS AND METHODS}

Fifteen male rats of wistar strain (Rattus norvegicus) were procured and bred in the experimental animal house of the College of Health Sciences, University of Port Harcourt Nigeria. The rats were fed with growers mesh (Sanders Feed, Port Harcourt) and tap water was provided ad libitum until they weighed between $200 \mathrm{~g}-300 \mathrm{~g}$.

The rats were divided into three groups of five rats each. The first group (Group A) was given $0.05 \mathrm{ml}$ of Halofantrine $1100 \mathrm{~g}$ body weight which corresponds to the manufacturer recommended therapeutic dose of $8 \mathrm{mg} / \mathrm{kg}$ body weight. The second group (Group B) was given $0.10 \mathrm{ml}$ of Halofantrine $1100 \mathrm{~g}$ body weight, which corresponds to twice the therapeutic dose of Halofantrine. The third group (Group C) was given $0.05 \mathrm{ml}$ physiological saline $/ 100 \mathrm{~g}$ body weight and served as 
the control. The three doses were given at six hourly intervals to each rat in all the groups.

The rats were sacrificed on the fifth day and the testes dissected out, blotted dry and the following parameters measured; length, width and weight. The shape and colour of the testes were observed with the aid of a hand lens and the naked eye. The tissues were fixed with 10\% formaldehyde, sectioned and stained with haematoxyline and cosin using standard procedures and then examined histologically.

The results obtained were then subjected to statistical analysis using analysis of variance; means and standard deviations were also determined. The results are as presented in Table $I$ and Plates I, II and 111.

\section{RESULTS}

Gross morphology

There were no obvious differences in the shape and colour of the testes in the three rat groups either with the naked eye or with aid of a hand lens. Table 1 shows the effects of Halofantrine on the length, width and weight of the testes in the three rat groups. The Table also shows the mean and standard deviations of the parameters measured. The results when subjected to statistical analysis using analysis of variance, revealed that no significant differences for the length and weight of the testes among the three rat groups ( $p$ $>0.05)$. However, there were significant differences $(p<0.05)$ among the three rat groups with respect to testicular width.

\section{Histology}

Plates I (a and b) II and III (a and b) show micrographs of the effect of Halofantrine on the histology of the testes for the various rat groups. The following effects were observed among the three rat groups.

\section{Group C (Control)}

The testes showed the tunica albuginea closely followed by the tunica vasculosa with the seminiferous tubules in various shapes. The tubules also show various stages of spermatogenesis. Between each tubule is an interstitial layer, which contains interstitial cells. Slight areas of mitotic divisions were observed (Plates la and 1b).

\section{Group A (Therapeutic Dose)}

The testes also showed the presence of tunica albuginea and tunica vasculosa. The seminiferous tubules also appeared in various shapes and sizes with increase tubular cellularity. The tubules showed more stages of spermatogenesis when compared with the control groups. More immature spermatogenic cells were also observed with more mitotic divisions. Mature cells were reduced in number when compared with the control groups. More interstitial cells were observed in the interstitial spaces and areas of tubular damage were also observed (Plate II).

\section{Group B (Double Therapeutic Dose)}

The testes also showed the presence of tunica albuginea and tunica vasculosa. There were however, more prominent immature spermatogenic cells when compared to the two former groups. There was denudation of cells from compartment to the center to the tubules. Mature cells were reduced in number and a lot of mitotic activities were observed (Plate IIIa and IIIb). There were also patchy areas of tubular damage observed. Towards the tunical albuginea there was atrophy of the tubules.

Table 1: Eflect of Halofantrine on testicular length, width and weight in mature wistar rats $($ with $n=5)$

\begin{tabular}{|c|c|c|c|}
\hline & Testicular leng(h) $\mathrm{m}$ ) & Testicular widih $(\mathrm{mm})$ & Testicular weight (g) \\
\hline $\begin{array}{c}\text { (iroup } \mathrm{C} \\
\text { Control }(n=5)\end{array}$ & $\begin{array}{c}1.900 \pm 0.158 \\
(1.700-7.100)\end{array}$ & $\begin{array}{c}0.940 \pm 0.084 \\
(0.80-10) \\
\end{array}$ & $\begin{array}{c}1.6550 \pm 0.4559 \\
(1.080-2.00) \\
\end{array}$ \\
\hline $\begin{array}{c}\text { Group } \mathrm{A} \\
(0.05 \mathrm{ml} / 100 \mathrm{~g})(\mathrm{n}=5) \\
\text { (Therapcutic Dose) }\end{array}$ & $\begin{array}{c}1.660 \pm 0.5857 \\
(0.70-2.10)\end{array}$ & $\begin{array}{c}0.680 \pm 0.2381 \\
(0.4-1.0)\end{array}$ & $\begin{array}{c}1.318 \pm 0.5979 \\
(0.74-2.32)\end{array}$ \\
\hline $\begin{array}{c}\text { Group B } \\
(0 . \operatorname{lml} / / 100 \mathrm{~g})(\mathrm{n}=5) \\
\text { (Double Therapeutic Dose) }\end{array}$ & $\begin{array}{l}1.84 \pm 0.2074 \\
(1.5-2.0)\end{array}$ & $\begin{array}{c}0.86 \pm 0.1517 \\
(0.7-1.0)\end{array}$ & $\begin{array}{c}1.478 \pm 0.4862 \\
(1.10-2.27)\end{array}$ \\
\hline $\begin{array}{l}\text { Significant differences } \\
\text { (ANOVA) }\end{array}$ & $\begin{array}{c}\text { No } \\
(p<0.05)\end{array}$ & $\begin{array}{c}\text { Yes. } \\
(p<0.05)\end{array}$ & $\begin{array}{c}\text { No } \\
(p>0.05)\end{array}$ \\
\hline
\end{tabular}




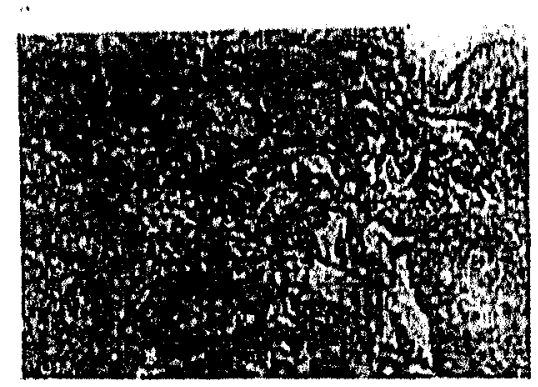

Plate Ia

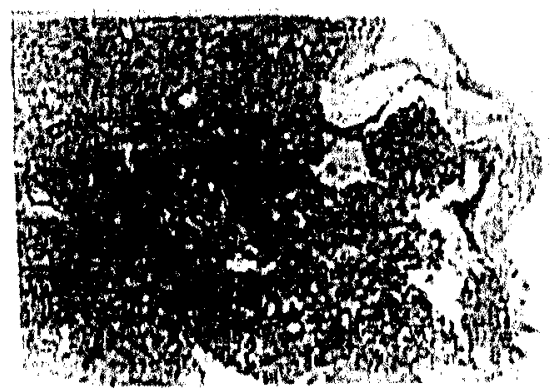

Plate II

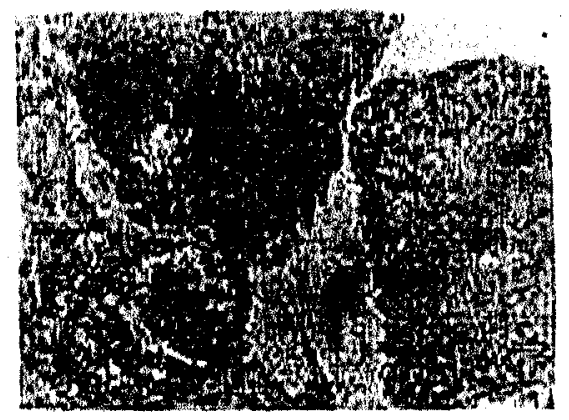

Plate IIIa

\section{DISCUSSION}

Halofantrine as a new anti-malarial drug with potentials to be the choice chemotherapy in future can be use in all forms of malaria. This is because it has met most criteria for an ideal anti-malarial drug (Hallwood et al 1989). It has a high cure rate, clears parasitaemia within 48 hours and reduces fever within 36 hours. At present cases of resistance are minimal, in addition the short half-life minimizes the risk of developing resistance. In addition its novel structure also minimizes the chances of crossresistance. These qualities make it better than

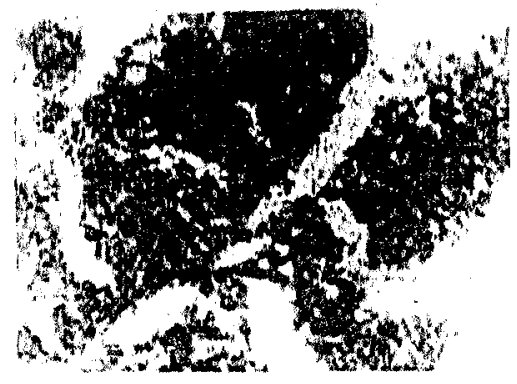

\section{Plate $1 b$}

Plate I (a and b) (control): Show tubules with various stages of spermatogenesis: Presence of interstitial cells between tubules; Slight areas of mitotic divisions are shown. Plate 1 a $\times 40$; Pate $\mathrm{lb} \times$ 100

Plate II (Therapeutic dose): Tubules show more stages of spermatogenesis when compared to the control group; Presence of more immature sperm cells with more areas of mitotic divisions. Plate II $\times 100$.

Plates III (a and b) (Double Therapeutic dose): Show presence of more prominent immature sperm eells compared to the two other groups: Mature cells are reduced in number with lot of mitotic activities. Plate III a $\times 10$ : Plate III b $\times 100$

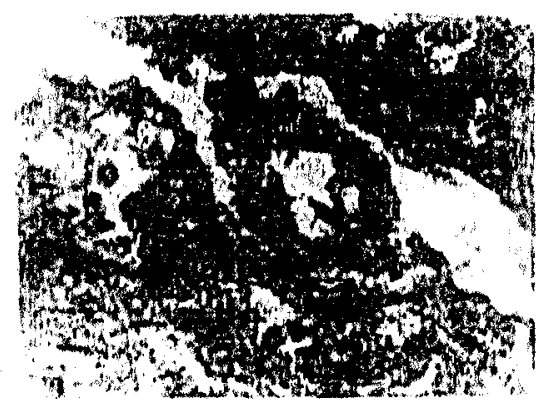

Plate IIIb

chloroquine, which has been in use for quite a long time in the treatment of malaria.

The results of this study however indicate that Halofantrine could cause some inflammatory changes in the rat testes. This was shown by the increased cellularity and widening of interstitial area. These changes were apparently dose dependent. The inflammatory reaction resulted in the testicular width between pairs of rat groups being significantly different (p. <0.05) More immature spermatocytes were also observed in the experimental rat groups. Rats given double the therapeutic dose (group B) 
showed tubular atrophy, which is an indication of degenerative changes. The presence of increased number of immature spermatocytes is an indication of increased spermatogenesis. This implication of this is that an increased number of immature spermatocytes occurs resulting in the reduction of viable sperms leading to reduced fertility. Morphologically, no differences were observed in the testes between the three rat groups with the naked eye and the aid of a hand lens. The histological changes observed above are therefore not apparent grossly.

The histological changes highlighted above could not result from an over dose of Halofantrine. This is because the dosage regimen given to the rats were based on their body weight: rats in group $A$ were given the therapeutic dose of the drug as recommended by the manufacturers, while the rats in Group B were given double the therapeutic dose. This is for the purpose of comparison. These histologic changes were however seen in both group $A$ and group $B$ rats though they were more acute in group $\mathrm{B}$ rats.

In conclusion, Halofantrine apparently increases spermatogenesis and could possibly cause some degenerative changes in the seminiferous tubules at higher doses. It is uncertain however if these changes are reversible. On account of the endemicity of malaria and the fact that Halofantrine could be administered as often as malaria attacks occur our findings should be taken seriously. More studies are however needed to determine the possible chronic effects of Halofantrine.

\section{REFERENCE}

Abila, B and Ikueze , R. (1989): Effects of Clemastine, Ketotifen and Prednisolone on Chloroquine induced Pruritus. Journal of Tropical Medicine and Hygiene 92,356-359.

Akpa, O. A. and Singh, S.P. (1992): Teratogenic effect of chloroquine on Leydig cells of Mature Wistar rats. $1^{\text {st }}$ National conference of Anatomical Society of Nigeria, Kano September 21-26.

Cook,G.C. (1988) Prevention and treatment of Malaria. In: Infection Today. A Lacent review. London pp. 631-77
Ekpechi, O.L. and Okoro, A.N. (1964): A pattern of Pruritus due to Chloroquine. Archives of Dermatology 89, 631-632.

Ezeamuzie, I.G.; Igbigbi, P. S.; Ambakederemo, A. W. Abila; B. and Nwaejike, N. (1991): Halofantrine induced Pruritus Amongst subjects who itch to chloroquine. Journal of Tropical Medical and Hygiene 94, 184-188.

Hallwood, P.N. Horton, R.J.; O'Sullivan, K.M. and Parr., S.N (1989): Halofantrine and Pruritus. Lancet II, 397-398.

Noronha, C. ; Okanlawon A. and Ashiru, O. (1991): Chloroquine: An Approach to the development of a female contraceptive in developing countries, West African Journal of Anatomy Vol. 1 (12), p. 66

Okalanwo, O. A., Noronba, C.C. Ashiru, O.A. (1990): the effects of chloroquine on peripheral levels of testerone gonadotropins and sperm motility. West African Journal of Pharmacology and Drug Research 9:31 33.

Olatunde, I.A. (1969): Chloroquine-induced Pruritus in Lagos, Nigeria, Journal of Nigerian Medical Association 6, 23-33.

Olatunde, 1.A. (1977): The Practical and Therapeutic Implications Chloroquine induce Pruritus in Tropical Africa. African Journal of Medicine and Medical Sciences. 6, 27-31

Osifo, N.G. (1984): Chloroquine-induced Pruritus Among Patients with Malaria. Archives of Dermatology 120 80-82.

Solako, L.A. (1984): Toxicity and Side -effects of Anti-malarials in West Africa. A critical Review. Bulletin of the World Health Organization 62 (Suppl.) $63-68$.

Sowunmi, A.; Walker, O. and Salako, L.A (1989): Pruritus and Anti-malarial Drugs in Africans. Lancet II, 213. 